University of Massachusetts Amherst

ScholarWorks@UMass Amherst

Communication Graduate Student Publication

Series

Communication

2021

The Co-Construction of Campaign Argumentation on U.S.A. Late-

Night Talk Shows

Menno H. Reijven

University of Massachusetts Amherst, mreijven@umass.edu

Follow this and additional works at: https://scholarworks.umass.edu/communication_grads_pubs

Reijven, Menno H., "The Co-Construction of Campaign Argumentation on U.S.A. Late-Night Talk Shows" (2021). Journal of Argumentation in Context. 14.

https://doi.org/10.1075/jaic

This Article is brought to you for free and open access by the Communication at ScholarWorks@UMass Amherst. It has been accepted for inclusion in Communication Graduate Student Publication Series by an authorized administrator of ScholarWorks@UMass Amherst. For more information, please contact scholarworks@library.umass.edu. 
Reijven, M. H. (2021). The Co-Construction of Campaign Argumentation on U.S.A. Late-Night Talk Shows. Journal of Argumentation in Context, 10(3), 397-417.

\section{The Co-Construction of Campaign Argumentation on U.S.A. Late-Night Talk Shows}

Menno H. Reijven, University of Amsterdam

This study shows that when presidential candidates visit, late-night talk show discourse is argumentative, and that this argumentation is co-constructed by the host and the candidate. Through their questions, hosts implicitly invoke arguments by casting doubt on the candidate's presidential bid. By treating the host's questions as critical questions expressing skepticism whether people should vote for the candidate, politicians prototypically use two types of argument schemes to defend their case. First, to argue that their policy proposals are needed, candidates use complex problem-solving argumentation. Second, to maintain that they have the skills and character to succeed as president, candidates use symptomatic argumentation. In their response, candidates also deal with other critical questions belonging to the argument scheme invoked through the host's question. Which critical questions of that argument scheme the candidate addresses in addition to the one posed by the host depends on the type of question the host has asked.

Key words: argument scheme; complex problem-solving argumentation; Entertainment-Political Interview; late-night talk show; political argumentation; pragma-dialectical theory of argumentation; symptomatic argumentation; U.S.A. presidential elections.

\section{Introduction}

Back during the 2000 U.S.A. presidential elections, late-night talk show host David Letterman, who invited both the Republican and Democratic candidate for the presidency onto his show, boasted that "the election will be decided here" (quoted in Niven, Lichter, and Amundson 2003:118). Today, campaign appearances on late-night talk shows have become standard practice for any presidential hopeful to garner the votes they need to become elected president. Interestingly, while politicians visit these shows for political purposes, late-night talk shows have primarily an interest in entertaining their audiences, mostly accomplished through interviewing celebrities (Loeb 2015).

Following Parkin (2014), we identify political appearances on late-night talk shows as a type of political interview. As entertainment remains yet a central feature of these interviews, we refer to them as Entertainment-Political Interviews (EPIs, see Reijven, Grimshaw, and Dori- 
Hacohen 2020). Whereas the literature about politicians' participation in news interviews has started in the 1980s (see Blum-Kulka 1983) and has been studied in various research traditions of language and social interaction (consider e.g., Andone (2013, pragma-dialectics), Clayman and Heritage (2002, conversation analysis) and Weizman (2008, discourse pragmatics)), the research on politicians' visits to late-night talk shows is scarcer (cf. Loeb 2017; Grimshaw and Reijven 2021; Reijven, Grimshaw, and Dori-Hacohen 2020). Being campaign discourse, the discourse of EPI should be seen as argumentative. Candidates' appearances on the EPI are part of their attempt to convince the U.S.A. electorate to vote for them in the upcoming presidential election. Yet, work is also lacking regarding the argumentative dimension of the EPI (however, see Lauerbach 2007).

In this article, we study the interaction between the host and a U.S.A. presidential candidate as an argumentative exchange where the host casts doubt on the candidate's bid for the presidency. First, in section 2, we review research on political appearances on late-night talk shows. Then, in section 3, we introduce the conceptual framework and data used for this study. Next, we assess two argumentative discourses in the EPI: on policy (section 4) and on character (section 5). We argue that policy is discussed through problem-solving argumentation, which is a subtype of causal argumentation (Garssen 2017), whereas character is discussed through symptomatic argumentation (Van Eemeren and Kruiger 2015). These argument schemes are central to the prototypical argumentative patterns (Van Eemeren 2018) in the EPI.

\section{Politicians' Campaign Appearances on Late-Night Talk Shows}

Appearing on late-night talk shows is part of politicians' strategy to convince voters to vote for them (Molek-Kozakowska 2013). The entertainment format should help their bid for gaining the presidency. Generally, the audiences of these shows are younger, less educated and not very 
interested in politics (Feldman and Young 2008; Parkin 2014). Moreover, as politicians can target specific audiences, and as each late-night talk show has a fairly distinct demographic (Parkin 2014), appealing to the electorate through late-night talk shows can be effective. In this regard, late-night talk shows can be an important vehicle to disseminate political knowledge among the general public as it also connects with people who are not receiving traditional political programming (Baum 2005).

However, the kind of political information spread through late-night talk shows is different than provided by traditional venues. At the EPI, political talk is made more entertaining for the audience through the personalization of politics (Collins 2014), which means that there is a lot of talk about the "experiences, feelings or intentions" of the politician (Molek-Kozakowska 2013: 331). Candidates can be sociable with the host and manage their impressions to construct a sense of authenticity and social closeness (Molek-Kozakowska 2013). Thus, the casual atmosphere of the late-night talk show makes it feel for people that they are figuring out who the politicians featured really are rather than just learning about policy positions (Collins 2014). Arguably, this has led to a change in criteria to assess presidential candidates (Collins 2014). Moy, Xenos and Hess (2006) have shown that the audience is primed to focus on character traits, instead of policy, to evaluate a candidate. Moreover, most talk is co-constructed by the host and the politician in order to elicit laughter (Eriksson 2010). Thus, these shows seem to offer the electorate little insight into politics itself. Rather than providing political information and critical argumentation, there is superficial coverage of a wide variety of topics to avoid the audience getting bored, and the emphasis of this talk is on speculation and drama (Molek-Kozakowska 2013). For politicians, the late-night talk show thus is a relatively safe space: the host has generally an interest in entertaining 
their audience and securing the visits of celebrities rather than safe-guarding democratic principles (Molek-Kozakowska 2013).

Still, while late-night talk shows have a relaxed conversational atmosphere (Loeb 2015), hosts are sensitive to having a political guest, and adopt a somewhat more journalistic role compared to their normal celebrity interviews (Loeb 2017). Politicians are also able to present politically relevant characteristics and insert some political discourse as well (Baym 2013; Reijven, Grimshaw, and Dori-Hacohen 2020). Importantly, to be successful on these shows and be taken seriously by the audience as a politician, candidates need to skillfully balance personal talk and political discourse (Taniguchi 2011). Various studies have suggested that humor and sarcasm are used on these shows to express criticism and thereby creating some sort of adversarialness and accountability (e.g., Baym 2013). Moreover, as Lauerbach (2007) has argued, these shows can provide the audience with a comprehensive politically-relevant argument. In this regard, while there is a lot of joking going on, candidates also have to justify their positions. Therefore, it is essential to better understand what kind of arguments are advanced to defend the candidate's bid for the presidency on EPIs. This helps to understand which information is given to the electorate to make their voting choice in the election, and the role of the host in eliciting this information, in a genre focused on entertaining its audience.

\section{Conceptual Framework, Data and Methodology}

To study the argumentation advanced on EPIs, we take a pragma-dialectical perspective (e.g., Van Eemeren 2010, 2018). Central to understanding the kinds of argumentation advanced is the notion of argument scheme. An argument scheme is "the way in which the reason given in support of a standpoint is supposed to bring about a transfer of acceptance to the standpoint in a particular type 
of argumentation" (Van Eemeren 2018:7). Thus, the argument scheme clarifies which premises are left implicit in the argument such that the reason provided will successfully defend the standpoint. As argumentation is within pragma-dialectics conceptualized as a dialectical process in which the protagonist responds to doubts raised by an antagonist (e.g., Van Eemeren 2010, 2018), argument schemes are also differentiated based on their unique sets of questions required to check the validity of the inference. Based on these sets of premises and their associated critical questions, Van Eemeren and Kruiger (2015) identify three main types of argument schemes: symptomatic argumentation, argumentation based on a comparison, and causal argumentation. These schemes have various subtypes, each having premises and critical questions in addition to one of these three main types.

As candidates appear on late-night talk shows during their presidential campaign, the standpoint "you should vote for me" is one of their virtual standpoints (Van Eemeren et al. 1993). Through questions which cast doubt upon a candidate's bid for the presidency, hosts question a premise which supports this virtual standpoint. Thereby, the host invokes an argument scheme which includes the implied premise and its associated critical question(s). In their turn to respond to the host's question, the candidate has the opportunity to not only respond to the question posed by the host, but also to anticipate additional critical questions to their position which belong to that same argument scheme. Hence, by assessing which premises are invoked to anticipated criticisms in the response of the candidate, it is possible to reconstruct the argument scheme used. This can aid to determine the prototypical argument schemes (Van Eemeren 2018) in the EPI . Schemes are prototypical if their usage can be explained based on the structural organization of this activity type (Van Eemeren 2018). In this study, I focus on the argument schemes which are embedded within the question-answer structure of late-night talk shows, and which are therefore prototypical 
to this genre of communication. Thus, this amounts to describing the typical argumentative discourse on these shows and thus clarifies what kind of appeal to the electorate is made through these shows.

As a form of political communication, the EPI is unique in that it combines talk about policy with talk about the politician themselves. In the political domain, policy is characteristically defended through referencing desirable results of implementing this measure by employing pragmatic argumentation (Van Eemeren 2018). Regarding European Parliamentary Debates, Garssen (2017) shows that politicians also point out that there is a problem to be solved (and thus, problem-solving argumentation is used). In the EPI, candidates have to sell their policy proposals to the wider electorate, and thus a similar argument scheme is expected. However, they use the policy to attempt to get people to vote for them rather than vote for the policy directly. When the conversation is about the candidates themselves, candidates share information about themselves showing that they will be able to handle being president. Then, it can be expected that candidates show that they have the qualities it takes to be president and thus use symptomatic argumentation.

The data for this study is a corpus of recordings (and the transcriptions thereof) of presidential candidate appearances on broadcast late-night talk shows in the U.S.A. (i.e., The Tonight Show Starring Jimmy Fallon, Jimmy Kimmel Live!, and The Late Show With Stephen Colbert ) during the 2016 and 2020 presidential campaigns. ${ }^{1}$ This corpus is used as data for a larger research project on EPIs as a communicative genre (see e.g., Reijven, Grimshaw, and DoriHacohen 2020; Grimshaw and Reijven 2021), and more transcripts will be added in the future. The current corpus consists of 22 episodes. Five episodes are taken from the 2016 U.S.A. Presidential

\footnotetext{
${ }^{1}$ I want to thank Gonen Dori-Hacohen, Eean Grimshaw, Maryam Mullenix and Anton Dinerstein for allowing me to use the transcriptions they have made for this corpus.
} 
Campaign. ${ }^{2}$ The remaining 17 episodes analyzed took place in 2019 , leading up to the Democratic primaries, showcasing a variety of Democratic candidates. ${ }^{3}$

For this study, we took two methodological steps. First, we determined whether a turn of a candidate was argumentative. If a textual element is argumentative, this means that it is concerned with acceptability, rather than comprehensibility (Snoeck Henkemans, 2001; Van Eemeren, 2018). Therefore, as election campaigns are antagonistic events, whenever the host asked a question concerning the candidate's bid for the presidency, we considered it as an expression of doubt calling for argumentation in the subsequent turn of the candidate. Second, we considered which argument schemes are then employed. Specifically, we determined what premise was questioned by the host and which other premises were defended by the candidate in their response. Next, in section 4, we discuss policy talk and show how the host and the candidate co-construct a form of problem-solving argumentation. In section 5, we look at talk about the candidates themselves and how symptomatic argumentation is advanced. In each case, we also consider how the question of the host affects the critical questions the candidate advances in their response turn.

\section{Question-Answer Sequences about Policy}

Question-answer sequences about policy start with the host eliciting from the visiting candidate an elaboration on their policy position. This can take place in various ways (e.g., excerpt 1-2).

1. Colbert-Yang, 06/25/2019

1. SC: You're in favor of empowering MMA Fighters. What does

$2 . \quad$ that mean?

\footnotetext{
${ }^{2}$ Two appearances each of Democratic nominee Hillary Clinton (one at Jimmy Kimmel Live! And one at The Tonight Show Starring Jimmy Fallon) and Republican nominee Donald Trump (both at The Tonight Show Starring Jimmy Fallon), and another one of Democratic runner-up Bernie Sanders (at Jimmy Kimmel Live!).

${ }^{3}$ The Democratic candidates currently included in the corpus are Kamala Harris, Julián Castro, Cory Booker, Elizabeth Warren, Pete Buttigieg, Andrew Yang, Marianne Williamson, and Joe Biden. Nine of these appearances were at The Late Show with Stephen Colbert, five at Jimmy Kimmel Live!, and three at The Tonight Show Starring Jimmy Fallon.
} 
2. Colbert-Buttigieg, 09/06/2019

1. SC: Can you negotiate with the Taliban, and if so, how would

2. you want us to get out [of Afghanistan]?

Each of the questions in excerpts 1-2 requests the candidate to elaborate on their policy position.

On the one hand, questions can just be requesting an elaboration on one of their policy positions.

In excerpt 1, Stephen Colbert assigns a known policy position to Andrew Yang, and next asks him what "empowering MMA fighters" (1:1) means. On the other hand, questions can presume a problem to be solved. In excerpt 2, Colbert posits a problem to Pete Buttigieg, that the U.S.A. is in Afghanistan, and asks him how he would "get [us] out" (2:2).

When the question focuses on a specific policy of the candidate, while candidates affirm their position, they characteristically elaborate and explain their specific position after having clarified the problem it is meant to address. Thus, candidates create a problem slot in their turn before discussing the policy, of which excerpt 3 is an example. During the 2016 U.S.A. presidential elections, Donald Trump campaigned for implementing a travel ban for Muslims. This proposal was controversial. Jimmy Fallon presumes this policy for Trump (3:1-2) and adds that Trump "probably knew that was gonna get some controversy" (3:5). By raising the "controversy" on the proposal, Fallon raises that some people have doubts, and as it is a b-event statement (Labov and Fanshel 1977), Trump is requested to comment on his commitment to this policy.

3. Fallon-Trump. $01 / 11 / 2016$

1. JF: I mean the Muslim thing is - not allowing any Muslims into

2. $\quad$ the United States

3. DT: On temporary basis. Temporary.

4. $\quad$ ((lines omitted))

5. JF: but you probably knew that's gonna get some controversy

6. DT: I did. I did. But you know there is something happening.

7. And we are talking about on the short-term basis. Temporary.

8. But Jimmy there is something happening out there. There's

9. hatred. You look at what's going on. Look at Paris. And

10. look at all of the. Look at what happened at Los Angeles 
11. just recently. And I mean look at the World Trade Center.

12. People flying airplanes into the World Trade Center? Into

13. the Pentagon?

In his response, Trump accepts that he still favors his travel ban for Muslims as he acknowledges that the plan has met criticism (3:6). Next, Trump employs the discourse markers "but" (to undermine something previously asserted, Fraser and Malamud-Makowski 1996) and "you know" (to get the audience onto the speaker's train of thought, Fox Tree and Schrock 2002). Trump explains that "there is something happening" (3:6) and specifically, that "there's hatred" (3:8-9). Next, he asks everyone to "look at what is going on" (3:9), like what happened in "Paris", "Los Angeles", "the World Trade Center" and "the Pentagon" (3:9-13). Thus, Trump urges people to consider what is going wrong in the world. Upon receiving this question, Trump took a step back to discuss the problem at hand. Trump showed the relevance of his proposal. Only later, he addressed Fallon's point that the plan is "controversial" by stating that many people agree with him (not shown).

For questions which presuppose a problem, only if the presupposed problem is disagreed upon a problem slot is created, as in excerpt 4 . In the preface to his question, Kimmel suggests a problem which Sanders' measure of limiting the income of rich Americans should solve. However, as Sanders disagrees with Kimmel that this is the problem he aims to address, he creates a problem slot through providing a preface to his response.

4. Kimmel-Sanders, 05/27/2016

1. JK: We talked about the income inequality and the top one 2. percent having huge percentage of the money. Do you think

3. there should be a limit on how much an American can make?

4. BS: I would approach it another way. I think when we have

5. cities like Flint Michigan where children, and I gotta

6. tell you I was there, it was one of the most painful

7. things I've ever experienced listening to parents who tell

8. me about what happens to the cognitive capabilities of 
9. their children when they are poisoned by lead in the

10. water. That is painful. And it's not just Flint Michigan.

11. All over this country, we have deteriorating schools. We

12. have people who are not getting the healthcare they need,

13. not getting the educ- not getting the jobs. Unemployment

14. for kids, off the charts. And yet you have a handful of

15. people, you have the twenty wealthiest people in this

16. country, owning more wealth than the bottom half of

17. America. Hundred and fifty million people, Jimmy, and I

18. don't think that's what America should be about, and I do

19. believe we should raise taxes on upper income people and

20. large profitable corporations. That is my view.

Before posing his question, Kimmel provides a preface referencing an earlier conversation he has had with Sanders about "income inequality" and "the top one percent" (4:1-2). Following this, Kimmel asks whether there "should be a limit on how much an American can make" (4:3). Thus, Kimmel suggests that "income inequality" is the problem which Sanders attempts to resolve with his measure. Instead, Sanders responds with "I would approach it another way" (4:4), and next, rephrases the problem at hand. Sanders explains that in America, there are many social problems, like having "lead in the water," "deteriorating schools," people "not getting the healthcare they need," and "unemployment" (4:9-14). Thus, Sanders has initiated a problem slot to revise Kimmel's presupposition through a metacommunicative message (see Craig, 2016), as he describes how his subsequent utterances have to be interpreted.

After raising a number of examples of problems the U.S.A. currently faces, Sanders addresses Kimmel directly (4:17) and reflects on what he has just said (4:17-18) and categorizes it as wrong, closing his talk about the problem at hand. Next, Sanders turns to explaining the specifics of his policy, and thus how he plans to solve this problem. He specifies that the "limit on how much an American can make" (4:3) simply means to raise taxes on "upper income people and large profitable corporations" (4:19-20). Through metacommunication, Sanders marks the end of his turn: "that's my view" (4:20), clarifying that he has answered the question. 
Thus, next to candidates addressing their policy commitments to answer the question posed, they recurringly create a problem slot as well. Both elements are needed in this interaction. As a problem is laid out to the audience, not committing to a policy to overcome that problem could hurt the candidate's presidential bid. Yet, the electorate is potentially not aware of these underlying issues and thus they have to be mentioned to discuss the policy. It is also essential to recognize that the policy slot is made conditionally relevant ${ }^{4}$ by the question, as hosts ask about the candidate's policy position. This explains why this slot is present last: it completes the question-answer pair. In addition, this explains why candidates mark the opening of a problem slot in their speech.

Consider the following exchange between Colbert and Buttigieg (extension of excerpt 2) where in contrast to Sanders in excerpt 4, Buttigieg accepts the problem introduced by Colbert in his question. However, Buttigieg does not directly create a policy slot which would answer the question. Instead, he lists a number of preconditions to be met before he explains what kind of solution he would propose.

5. Colbert-Buttigieg, 09/06/2019

1. SC: Are they [the Taliban] trustworthy in your opinion?

2. Can you negotiate with the Taliban, and if so, how

$3 . \quad$ would you want us to get out [of Afghanistan]?

4. PB: Well, I think the important thing is to make sure that

5. we have a deal that works for our interests, that is

6. enforceable. So, do I trust the Taliban in terms of

7. thinking that they're like a nice or great group of

8. folks, I do not. But by definition, when you're making

9. peace with somebody, you're making peace with your

10. enemy. That's what it is to come to the table. To me,

11. the real problem is that the Afghan government - you

12. know, the legitimately elected Afghan government -

\footnotetext{
${ }^{4}$ Conditional relevance is a term used in Conversation Analysis (see, e.g., Schegloff 1968). This term refers to the fact that by the presence of a first element (in this case, a question), a second element is expected (in this case, a response to that question). The absence of this second pair part would therefore be noticeable to the participants. The conditionally relevant slot is thus the answer sought through the earlier question.
} 
13. has been on the sidelines of this process and I think

14. they need to be very much in the middle of it.

The question posed by Colbert presupposes that there is a problem with the U.S.A. being in Afghanistan, and thus, that the U.S.A. has to leave (5:1-3). Buttigieg starts his turn with the discourse marker "well" (5:4), signifying that what follows is not a direct response to the question (e.g. Schegloff and Lerner 2009). While he was asked to provide a policy position on Afghanistan, Buttigieg offers a set of preconditions for a good policy. Any deal with the Taliban should "work for our interests" and should be "enforceable" (5:5-6). Buttigieg thus offers insight into the standards any good plan should meet. In this way, he shows that he has considered multiple aspects of a solution, and thus suggests that his plan is not having any limitations. Here, Buttigieg has created an efficacy slot, in which he explains why he has the best possible plan. At the end of the excerpt, Buttigieg claims that "the real problem" (5:11) is that the "legitimately elected Afghan government" (5:12) has been sidelined, explaining why previous policies have failed. Finally, Buttigieg fulfills the policy slot requested through the question by claiming that he wants to put them "in the middle of it" (5:14).

In sum, candidate responses to questions about their policy position on the EPI have three distinct argumentative slots: candidates talk about the problem at hand, the plan they propose to resolve the issue, and how their proposal is the best one to do this. Although an argument for a policy on EPI does not always use all three, each is recurrently used. These argument slots line up well with the argument scheme characteristically used in the political domain: complex problemsolving argumentation (Garssen 2017:37). This argumentation is used to call for a particular course of action based on the identification of a problem, elaboration on how the proposal will solve this problem and by explaining that this proposal is feasible, with minimal disadvantages and better than rivaling proposals. 
Yet, the problem-solving argumentation on the EPI is different than in other political contexts. In the case of policy talk on the EPI, the audience is not called upon to vote on the proposal, but on the candidate. Therefore, as the standpoint being defended is "vote for me," the proposal put forward to the electorate is "electing this candidate based on proposal $x$ ". With the problem slot, candidates anticipate the question "is there a significant problem to begin with?" The policy slot deals with the fact whether the candidate can solve this problem through the specific plan they propose to implement. The efficacy slot considers the parameters of the proposal, whether it is feasible, has side effects or whether there are potentially better alternatives. The efficacy slot is particularly relevant in the context of a presidential campaign as candidates implicitly claim that what they propose is better than the solutions presented by their opponent(s).

As a result, the argument scheme used is grounded in the following critical questions (adapted from Garssen 2017):

1. Is there a significant problem?

2. Will the candidate solve the problem with their proposal?

3 . Is the action proposed by the candidate feasible?

4. Are there disadvantages to the proposed action?

5. Are there better means to solve the problem?

Based on these critical questions, policy argumentation can be reconstructed based on the following argument scheme:

1. You should vote for me in the presidential elections.

1.1a. There is a problem $\mathrm{Y}$, which should be solved.

1.1b. I will solve problem $Y$ through implementing policy $Z$

1.1a-b' You should vote for the candidate who solves problem Y by implementing $\mathrm{Z}$.

This reconstruction acknowledges that the argumentation advanced is inherently comparative. As in an election, a number of candidates fight each other in order to assume office, the candidates always, often implicitly, present themselves as the better option compared to their opponents. This is one of the criteria to assess the efficacy of the proposal: better means to solve 
the problem may have been proposed by someone else, which would undermine the premise that "you should vote for the candidate who solves problem Y by implementing Z."

This argument scheme is prototypical to the EPI. First of all, the questions and premises are unique to this context. As it is a campaign context, the focus is on electing the candidate based on their proposal rather than just the evaluation of the proposal itself. Rather than simply defending their proposal, candidates use it to defend their presidential bid. Second, how these argumentative exchanges are co-constructed by the host and the candidate is tied to the EPI. For example, characteristically, candidates include a policy slot in their response. Likely, this is because the question asked by the host is focusing on their policy position, and not providing this, would be evading the question as they leave a conditionally relevant element absent. This also explains why candidates usually include at least another slot in their turn as just providing one's position is not likely to be convincing. For an audience which is uncertain who to vote for, simply raising a measure without explaining the problem it is meant to address (critical question 1/premise 1.1a) or how it is better than alternatives (critical question 5/premise 1.1a-b') does not constitute a compelling reason to select one's preferred candidate. Additionally, the fact that generally the policy slot is produced last, although requested as answer through the question, can also be explained based on its conditional relevance. When fulfilling this slot, by having responded to the question, the host could take the floor again to ask their next question as the adjacency pair has been completed.

\section{Question-Answer Sequences about Presidential Qualities}


On EPIs, there is especially a lot of talk about the presidential qualities of the candidates, both in terms of character as well as their abilities to succeed as president. These arguments can be elicited in various ways, as shown in excerpts 6-8.

6. Fallon-Clinton, 09/17/2015

1. JF: Are you tough enough to be president?

7. Colbert-Biden, 09/05/2019

1. SC: Is there gonna be rough and tumble [at the Democratic

2. Debate] cause there's gonna be broad systemic change

3. [advocated by Warren] and what people say is

4. incrementalism [of Biden]. They're looking for a fight.

8. Colbert-Warren, 3/26/2019

1. SC: How liberal are you?

While each elicitation (excerpts 6-8) inquires about whether the candidate is qualified to take up the U.S.A. presidency, they do so in three different ways. First, hosts can advance doubts as in excerpt 6. Here, they presume a presidential quality (like "tough enough to be president," 6:1), but question whether the candidate meets this requirement. Second, hosts can advance criticisms like in excerpt 7 . Then, they presume that the candidate has a quality problematic to being president. For example, Colbert references the idea that Biden will not bring "broad systemic change", but only "incrementalism" (7:3-5). Earlier in the interview, Biden already asserted that he is not advocating "incrementalism," showing that this is a quality he does not want to identify with. Third, questions can invoke what the candidate themselves believes to be a desirable quality for a president, as in excerpt 8. Such attributions, like being "liberal" (8:1) for Elizabeth Warren, are characteristics the candidate wants to identify with. For Warren, running as a candidate on the left, she desires to be seen as liberal. However, for voters, it may not be clear why they would want to have a president with this attribute. 
In the case of doubts, the host raises a characteristic or ability relevant to the presidency and questions whether the candidate meets this requirement. Thus, candidates have to defend that they are able to become president. In the following excerpt (9), Marianne Williamson first affirms she meets the raised quality and implies it is relevant, and then positions herself accordingly showing how she meets this requirement.

9. Colbert-Williamson, 07/23/2019

1. SC: Would you be able to order other people to go kill our

2. enemies?

3. MW: Absolutely, I think that when you take an oath of office

4. as the President of the United States, part of that oath

5. means that you are Commander in Chief.

By asking whether Williamson "would be able to order" people to "kill our enemies" (9:1-2), Colbert presumes that the president of the United States should be able to order fighting enemies. He suggests that Williamson is not ready for the job. Williamson does not contest this requirement for the presidency and responds she is "absolutely" (9:3) able to give these orders. Next, she explains that she would be committed to the "oath" (9:3) the "Commander in Chief" (9:5) takes. She shows she knows the job and is ready to make these difficult calls. Thereby, she justified why she will be able to handle the tasks of the presidency.

Doubts usually do not come out of the blue. The doubts concerning Williamson's ability to order to kill were relevant as during the campaign she talked a lot about bringing peace and rarely mentioned war and fighting. Next, Williamson resituates the discussion on peace and explains why emphasizing peace is so important. Thereby, she addresses the source of the concerns towards her ability.

10. Colbert-Williamson, 07/23/2019 (excerpt 9 continued)

1. MW: But I think if you're going to talk about peace, you

2. can't just back up into peace. I have great respect for

3. the military. My father fought in World War Two. My 
4. critique of our national security agenda is not a

5. critique of the military, it's a critique of politicians

6. who have based our national security agenda as much on

7. short term profit maximization for defense contractors

8. as it has on any agenda for creating peace. When was

9. the last time you heard a politician talking about peace

10. on this planet in twenty years?

Continuing after affirming that America needs a president who can order to kill, Williamson elaborates on why she emphasizes peace so much. She argues that achieving peace, supposedly the ultimate goal, is more complicated than just having a strong military (10:1-2). While the military is doing a good job (10:2-3), she does critique "politicians" (10:5) who ignore peace altogether (10:9-10). Thus, after affirming Colbert's proposed required qualification for the presidency of being able to "order" to "kill", and after positioning herself having that ability, Williamson relativizes this claim and explains that being able to order to kill enemies is not the only ability a president should have. They should also be able to work towards peace through a solid agenda broader than just military action. In her talk, this shift was marked through the discourse marker "but" (10:1), often used to deny a previously affirmed proposition (Fraser and Malamud-Makowski 1996).

Williamson's strategy to first affirm the quality as relevant and then relativize its importance is recurringly adopted by candidates in response to doubts. As the host raises doubts which are circulating in public discourse, denying them is not an effective strategy. For example, in 2016, Donald Trump frequently implied Hillary Clinton would not be tough enough to be president of the U.S.A., making the question shown in excerpt 6, whether Clinton is "tough enough to be president," relevant. As shown in excerpt 11, Clinton employs a similar strategy as Williamson. First, she affirms having the trait whereafter she repositions this trait within the full palette of presidential qualifications.

11. Fallon-Clinton, 09/17/2015 
1. JF: Are you tough enough to be president?

2. HC: Yes, I think so. But, you know, look, you gotta be a lot

3. of different things to be a good president. You gotta

4. start with really understanding what people are going

5. through, and trying to figure out how you can help

6. everybody have a better shot at a future that they

7. deserve. That is my mission in this campaign and as

8. President. But there are problems in the world and there

9. are - believe it or not - some people who don't agree

10. with us and might cause some mischiefs. So you do have

11. to be prepared to do it in a sensible smart way. Not

12. bullying, you know, with a little more diplomacy.

When Fallon asks Clinton whether she is "tough enough to be president" (11:1), Clinton immediately affirms, thereby acknowledging this quality is relevant to being president (11:2).

Next, Clinton provides several discourse markers to indicate her shift away from just having to be "tough." With a "but"-clause (11:2), like Williamson, Clinton suggests she will amend her previously provided affirmation (Fraser and Malamud-Makowski 1996). Through "you know" (11:2), Clinton conveys that what follows has critical implications for her position (Jucker and Smith 1998). The marker "look" (11:2) is used to redirect the course of interaction (Sidnell 2007). Then, in contrast to Fallon's suggestion that presidents should just be "tough," Clinton claims that "you gotta be a lot of different things to be a good president" (11:2-3). Specifically, presidents should be able to "understand what people are going through" (11:4-5) and based on that, "figure out how [they] can help" (11:5). Similarly, "there are problems in the world" (11:8) which simply cannot be solved by just being "tough," but by using "diplomacy" instead of "bullying" (11:12). A president will not succeed by just being "tough;" Clinton implies that she has these other skills.

Both excerpts show two central argumentative elements. In the question, the host presumes a required quality for the presidency (i.e. a symptom of a good presidential candidate) and asks the candidate to explain whether they have this symptom (thus implying that they do not clearly seem to possess this characteristic). Both Williamson and Clinton confirmed that they have this quality, 
and thus also implied that it is relevant to being president. However, both of them raised additional characteristics to be taken into account and thus changed the argument proposed by the host. They marked this switch from the host's argument to their own through discourse markers. This type of question seems to generally invoke these two moves for the candidates: ascribing the mentioned quality to themselves and elaborating on further qualities they possess to present a convincing argument for why they are the right candidate to elect as president.

Consider the second type of questions introduced above, criticisms, where the host introduces a negative quality, which they presume the candidate possesses. The candidate will have to dissociate themselves from this trait, as it would undermine their bid for the presidency. The next excerpt (12) shows how Trump dealt with such a question in 2016.

12. Fallon-Trump, 09/16/2016

1. JF: Everyone's saying, oh is there a bromance between

2. Vladimir Putin and all this stuff. And what is the

3. celebrity nickname for you guys, and I thought of Vlump.

4. Vlump, I thought was good.

5. $\quad($ pause $))$

6. JF: You said, if he says great things about me, I'll say

7. great things about him.

8. DT: Well, look I don't know him and know anything about him

9. $\quad$ really. I just think if we get along with Russia, that's

10. not a bad thing - and you know, getting along with other

11. countries.

When Fallon tries to get Trump to defend his seemingly close relationship with Vladimir Putin, president of Russia, he first references what “everyone's saying” (12:1) and suggests Trump and Putin have "a bromance" (12:1). This first attempt at eliciting Trump's justification fails as a pause follows this turn (12:5). Second, he references what Trump has said about Putin (12:6-7), which functions as a question as it is a b-event statement (Labov and Fanshel 1977). Fallon implies that Trump is unpatriotic and un-American, qualities which a presidential candidate should not have. In response, Trump claims he "[doesn't] really know him" (12:8) and explains that "if we get along 
with Russia, that's not a bad thing" (12:9-10). Trump implicitly accepts the qualities suggested by Fallon as ones a president should not have and implies that he does not possess these undesirable qualities. After all, his answer, which undermines the presupposition in Fallon's question, is marked by the discourse marker "well," suggesting the response is not going along with the elicitation of the host (e.g., Schegloff and Lerner 2009). Instead, Trump immediately shifts his response to stressing a desirable quality he does possess. In his turn, Trump raises qualities he has, which are desirable for a U.S.A. president. He explains what he wants to achieve and thus makes clear that he has the U.S.A. interests in mind.

When advancing character argumentation in reply to criticism, the candidate recurringly first affirms the raised quality as undesirable and then dissociates themselves from having this quality. Typically, the negative quality was raised as the candidate's actions in the past could imply that they possess this quality. Hence, candidates have to explain why what they have done does not imply they possess the undesirable quality. Instead, like Trump, candidates introduce a quality which is desirable of presidents and which also aligns with the relevant behavior of the candidate under discussion.

The last type of character elicitations are attributions. Then, the candidate is asked to elaborate on some qualification they believe is desirable for a president of the U.S.A. to have. While it is presumed that the candidate has this qualification, it is not yet clear to the audience why this is a requirement (or preference) for the presidency. Consider excerpt 13, where Warren explains why she does not associate with "wealthy donors."

13. Colbert-Warren, 3/26/2019

1. SC: You've said, you won't call wealthy donors or attend

2. fancy fundraisers? Why won't you do that? And is that

3. just for the primaries or ever?

4. EW: So, look, I don't do any of this. I think the problem is 
5. that money has too much influence in Washington.

In response to Colbert referencing Warren's earlier remark that she would not "call wealthy donors" (13:1) or "attend fancy fundraisers" (13:1-2) and his follow-up question of "why" she does that (13:2) and for how long, Warren responds first by affirming that this quality pertains to her (13:3). Next, she explains why this quality should be required of all candidates for the presidency: "money has too much influence in Washington" (13:5). Thus, Warren argues for this quality becoming a standard in evaluating presidential candidates. Prototypically, in the case of attributions, candidates elaborate on the fact that this is a quality which should be required of presidents.

In sum, to talk about their presidential character, candidates may have to respond to three different types of questions which lead to them advancing different argumentative moves. First, in the case of doubts, the host presumes a quality to be presidential, but leaves it open whether the candidate possesses it. Implicitly, the candidate confirms that this is a presidential attribute and that they possess it, but they mostly elaborate upon which characteristics they possess in addition to this one. After all, a doubt came up as the candidate does not fully embody the presumed presidential quality. Second, in the case of criticisms, the host predicates a negative quality of the candidate. The candidate accepts that this is indeed an undesirable quality and imply that they do not possess that quality. Instead, they explain how what they have done is actually an indication of a quality a president should possess. Third, in the case of attributions, the host predicates a (from the candidate's perspective desirable) quality. Here, it is unclear to the audience whether this quality is generally desired of presidents, and this is what the candidates address in their response turn. 
These excerpts show that for character argumentation, the candidates advance symptomatic argumentation (Van Eemeren and Kruiger 2015). The critical questions implicitly addressed and shown in the previous excerpts belong to this argument scheme. Following this scheme, the following critical questions are relevant when the participants talk about the presidential character of the candidate (adapted from Van Eemeren and Kruiger 2015:706):

1. Is Y really typical of a good president?

2. Does the candidate actually possess quality $\mathrm{Y}$ ?

3. Are there additional qualities which one must have to be president?

4. Does the candidate possess qualities which are not presidential?

When advancing doubts, the host asks critical question 2 , while the candidate mainly provides an answer to critical question 3. Criticisms equal to asking critical question 4, but candidates mostly address critical question 2. Last, concerning attributions, the host asks critical question 1.

This results in the following argument scheme (adapted from Van Eemeren and Kruiger 2015) on the EPI.

2. You should vote for me in the presidential elections

2.1a. Presidents should have quality Y.

2.1b. Candidate $\mathrm{X}$ has quality $\mathrm{Y}$.

2.1a-b' You should vote for the candidate who has quality Y.

Like the problem-solving argument scheme discussed in the previous section, this argument scheme is also prototypical to the EPI. As the argument is also co-constructed by the host and the candidate, how the scheme plays out in practice depends on the interaction itself. As shown, depending on the question asked by the host, the candidate will elaborate upon different premises from this argument scheme.

\section{Conclusion}


In this article, we have shown that candidates prototypically employ two types of argument schemes. First, we looked at segments initiated by the host through a question, eliciting talk about policy, and showed that this results in problem-solving argumentation. Second, we considered questions which started talk about the candidate's character, resulting in symptomatic argumentation. First and foremost, this study contributes to understanding the EPI as an argumentative context. It shows that EPI discourse provides its audience with two types of reasons to vote for the candidate. This fits with what was identified with the core of the EPI: the conversation is both about the candidate's politics as well as their personality. The candidates take away doubts regarding their plans and their ability to govern. Hence, even though late-night talk shows are centered around entertainment and jokes, there is political argumentation directed at the audience.

Besides showing the schemes used to convince the audience to vote for the candidate running for the U.S.A. presidency, we also claimed that these schemes are prototypical and thus that this argumentative discourse is connected to the context of the EPI. This study has shown that hosts of late-night talk shows and presidential candidates co-construct argumentative discourse: which argumentation is advanced, depends on the question posed by the host. Moreover, even how the argumentation is expanded by the candidate depends on the formulation of the question by the host. Each prototypical argument scheme corresponds to a number of slots (which correlate with the critical questions/premises of the argument scheme) which can be utilized in the answer turn to the question. Given the host's formulation of the question, the candidate invokes a number of these slots in their response turn. One of these slots is made conditionally relevant by the question, but other critical questions may need to be addressed as well. Hence, the two argument schemes 
shown (i.e., problem-solving and symptomatic argumentation) are commonly used because they are intertwined with the question-answer sequences in this genre.

As this research is a first step at better understanding the EPI argumentatively, there are some areas which should be addressed by future research. In showing how the host interactionally partakes in the construction of the argumentative discourse, a better description can be made of the dialectical nature of this genre. That is, the dialectical procedure as it unfolds in situ within this genre can be elucidated. On the one hand, future research should address how candidates utilize their slots to defend each premise as well as how the different arguments work together within this argumentative discourse. On the other hand, to fully characterize the dialectical nature of this genre, a more detailed analysis is required on the interplay between the host's questions and the response given by the candidate. Future research should more closely investigate how this argumentation is expanded through follow-up questions by the host. Future studies could employ the concept of dialectical profiles (Van Eemeren, Houtlosser and Snoeck Henkemans 2008) to further investigate these issues. This study has not addressed how the argumentation is designed to also attack the candidate's opponent, which is another feature that requires scholarly attention.

Concerning argumentation more generally, we suggest that questions in interviews, if there is a virtual standpoint at stake for the interviewee, should be interpreted as critical questions of a prototypical argument scheme for that context. Namely, through the questions of the host which could undermine the presidential candidates' standpoint "you should vote for me" the prototypical argument schemes for the EPI (i.e. problem-solving and symptomatic) are implicated and subsequently used by the candidate to defend their candidacy. Another suggestion coming forth out of this study is that moving between responses to different critical questions requires discursive work. Candidates use discourse markers and metacommunication to create response slots to 
different critical questions. Studies will have to do more research into the relation between discourse markers and metacommunication, and switching from one critical question to the next, and whether the order in which the questions are addressed makes a difference.

Overall, this research contributes to the study of the EPI and, specifically, provides a starting point to determining whether (and how) the EPI contributes to U.S.A. democratic discourse. Albeit not the dominant talk on the show, late-night talk shows offer their audiences some argumentation relevant to evaluating a presidential candidate. Due to the candidates' and hosts' argumentative work, on these shows policy and qualifications are discussed with some critical depth. Perhaps, this genre, while not really political given all the buffoonery going on, may after all still be able to provide some valuable information to segments of the U.S.A. electorate and change their minds through reasonable discourse.

\section{Acknowledgements}

I want to thank Frans van Eemeren, Alena Vasilyeva and the two anonymous referees for their supportive and valuable feedback.

\section{References}

Andone, Corina. 2013. Argumentation in Political Interviews. Analyzing and Evaluating Responses to Accusations of Inconsistency. Amsterdam, NL: John Benjamins.

Baum, Matthew A. 2005. "Talking the Vote: Why Presidential Candidates Hit the Talk Show Circuit." American Journal of Political Science 49(2): 213-34.

Baym, Geoffrey. 2013. “Transformations in Hybrid TV Talk: Extended Interviews on The Daily Show (.Com)." In Media Talk and Political Elections in Europe and America, ed. by Mats 
Ekström and Andrew Tolson, 63-86. London, UK: Palgrave Macmillan.

Blum-Kulka, Shoshana. 1983. “The Dynamics of Political Interviews.” Text 3(2): 131-53.

Clayman, Steven E., and John Heritage. 2002. The News Interview: Journalists and Public

Figures on the Air. Cambridge, UK: Cambridge University Press.

Collins, Sue. 2014. "Performing Ordinary : Politicians, Celebrity, \& the Politics of

Representation on Entertainment Talk.” The Popular Culture Studies Journal 2(1\&2): 10939.

Craig, Robert T. 2016. "Metacommunication." In The International Encyclopedia of Communication Theory and Philosophy, ed. by Klaus B. Jensen and Robert T. Craig, online. Routledge. doi: 10.1002/9781118766804.wbiect232.

Van Eemeren, Frans H. 2010. Strategic Maneuvering in Argumentative Discourse. Extending the Pragma-Dialectical Theory of Argumentation. Amsterdam, NL: John Benjamins.

Van Eemeren, Frans H. 2018. Argumentation Theory: A Pragma-Dialectical Perspective. Cham, $\mathrm{CH}$ : Springer.

Van Eemeren, Frans H., Rob Grootendorst, Sally Jackson, and Scott Jacobs. 1993.

Reconstructing Argumentative Discourse. Tuscaloosa, AL: The University of Alabama Press.

Van Eemeren, Frans H., Peter Houtlosser, and A. Francisca Snoeck Henkemans. 2008.

"Dialectical Profiles and Indicators of Argumentative Moves." Journal of Pragmatics 40(3): 475-93.

Van Eemeren, Frans H., and Tjark Kruiger. 2015. “Identifying Argumentation Schemes.” In Reasonableness and Effectiveness in Argumentative Discourse: Fifty Contributions to the Development of Pragma-Dialectics, ed. by Frans H. van Eemeren, 703-12. Cham, CH: 
Springer.

Eriksson, Göran. 2010. "Politicians in Celebrity Talk Show Interviews: The Narrativization of Personal Experiences.” Text and Talk 30(5): 529-51.

Feldman, Lauren, and Dannagal Goldthwaite Young. 2008. "Late-Night Comedy as a Gateway to Traditional News: An Analysis of Time Trends in News Attention among Late-Night Comedy Viewers during the 2004 Presidential Primaries." Political Communication 25(4): $401-22$.

Fox Tree, Jean E., and Josef C. Schrock. 2002. "Basic Meanings of You Know and I Mean." Journal of Pragmatics 34: 727-47.

Fraser, Bruce, and Monica Malamud-Makowski. 1996. "English and Spanish Contrastive Discourse Markers.” Language Sciences 18(3-4): 863-81.

Garssen, Bart. 2017. "The Role of Pragmatic Problem-Solving Argumentation in Plenary Debate in the European Parliament." In Prototypical Argumentative Patterns. Exploring the Relationship between Argumentative Discourse and Institutional Context, ed. by Frans H. van Eemeren, 31-51. Amsterdam, NL: John Benjamins.

Grimshaw, Eean, and Menno H. Reijven. 2021. "U.S. Presidential candidates' use of the firstperson plural on Entertainment-Political Interviews." In Fresh Perspectives on Major Issues in Pragmatics, ed. by Monika Kirner-Ludwig, pp. 61-81. Routledge.

Jucker, Andreas H., and Sara W. Smith. 1998. “And People Just You Know like 'Wow'. Discourse Markers as Negotiating Strategies.” In Discourse Markers: Descriptions and Theory, ed. by Andreas H. Jucker and Yael Ziv, 171-201. Amsterdam, NL: John Benjamins. Labov, William, and David Fanshel. 1977. Therapeutic Discourse: Psychotherapy as Conversation. New York, NY: Academic Press. 
Lauerbach, Gerda. 2007. "Argumentation in Political Talk Show Interviews." Journal of Pragmatics 39(8): 1388-1419.

Loeb, Laura. 2015. "The Celebrity Talk Show: Norms and Practices." Discourse, Context \& Media 10: 27-35.

Loeb, Laura. 2017. "Politicians on Celebrity Talk Shows." Discourse, Context \& Media 20: 14656.

Molek-Kozakowska, Katarzyna. 2013. "The Late-Night TV Talk Show as a Strategic Genre in American Political Campaigning." In Analysing Genres in Political Communication:

Theory and Practice, ed. by Piotr Cap and Urszula Okulska, 321-43. Amsterdam, NL: John Benjamins.

Moy, Patricia, Michael A. Xenos, and Verena K. Hess. 2006. "Priming Effects of Late-Night Comedy." International Journal of Public Opinion Research 18(2): 198-210.

Niven, David, Robert R. Lichter, and Daniel Amundson. 2003. "The Political Content of Late Night Comedy." Harvard International Journal of Press/Politics 8(3): 118-33.

Parkin, Michael. 2014. Talk Show Campaigns. Presidential Candidates on Daytime and Late Night Television. New York, NY: Routledge.

Reijven, Menno H., Eean Grimshaw, and Gonen Dori-Hacohen. 2020. “'That's Not Funny!' Identity and the organization of interaction on USA entertainment-political interviews." Discourse, Context \& Media 35: 100386.

Schegloff, Emmanuel A. 1968. "Sequencing in Conversational Openings." American Anthropologist 70(6), 1075-1095.

Schegloff, Emmanuel A., and Gene H. Lerner. 2009. "Beginning to respond: Well-prefaced responses to wh-questions." Research on Language and Social Interaction 42(2), 91-115. 
https://doi.org/10.1080/08351810902864511

Sidnell, Jack. 2007. “'Look'-Prefaced Turns in First and Second Position: Launching, Interceding and Redirecting Action." Discourse Studies 9(3): 387-408.

Snoeck Henkemans, A. Francisca. 2001. "Argumentation, Explanation and Causality. An Exploration of Current Linguistic Approaches to Textual Relations." In Text Representation: Linguistic and Psycholinguistic Aspects, ed. by Ted J. M. Sanders, Joost Schilperoord and Wilbert Spooren, 231-46. Amsterdam, NL: John Benjamins.

Taniguchi, Masaki. 2011. “The Electoral Consequences of Candidate Appearances on Soft News Programs." Political Communication 28(1): 67-86.

Weizman, Elda. 2008. Positioning in Media Dialogue: Negotiating Roles in the News Interview. Amsterdam, NL: John Benjamins.

Author's address

Menno H. Reijven

Faculty of Humanities

University of Amsterdam

Spuistraat 134

1012VB Amsterdam

The Netherlands

m.h.reijven@uva.nl 